\title{
Exploration and Practice of New Engineering Courses in Local Universities
}

\author{
Sun Hongxia* \\ Xinglin college, Nantong University, China
}

*Corresponding Author: Sun Hongxia, Xinglin college, Nantong University, China

\begin{abstract}
The integration of University and local development is not only a means to realize the connotative index of higher education, but also an important way to construct new engineering courses in local colleges and universities. By analyzing the role-playing and reform constraints of local universities and regional government and enterprise colleges in the construction of new engineering courses, starting from the basic characteristics of new engineering construction and the new demand for engineering talents, taking Xinglin College of Nantong University as an example, this paper expounds the basic ideas of local colleges and universities to develop new engineering through school local integration.
\end{abstract}

Keywords: school local integration; local universities; new engineering

\section{INTRODUCTION}

At present, China is striding forward from a big industrial country to an industrial power, and the industrial development is closely connected with engineering education. The new engineering program put forward by the Ministry of education is the fundamental policy for China's engineering education to grow into a powerful engine of national innovation driven development. So far, the Ministry of engineering has put forward a new concept of "action guide for colleges and universities" and "Fudan University" and "Fudan University"[]. The exploration and practice of new engineering courses in Colleges and universities all over the country are also in full swing, gradually becoming a prairie fire.

\section{ConNotation OF NeW EngineERing CONSTRUCTION}

The connotation of new engineering is to cultivate future diversified and innovative outstanding engineering talents with the guidance of moral cultivation and the construction concept of responding to changes and shaping the future. It includes three meanings of "inheritance and innovation", "cross and integration" and "coordination and sharing". "Inheritance and innovation" mainly refers to the transformation, transformation and upgrading of traditional disciplines based on the current and future industrial development trend, including the sublimation of talent cultivation concept, the reform of system and mechanism, and the innovation of training mode; "Cross and integration" mainly refers to the new disciplines based on the interdisciplinary and industry university research integration, including the intersection and integration between existing engineering disciplines, engineering disciplines and other disciplines; "Coordination and sharing" mainly refers to the formation of collaborative education mode of university subject, government led, industry guidance and enterprise participation through the diversified subject relationship of collaborative engineering education, so as to promote the co construction and sharing of high-quality education resources and educational achievements of new engineering. It can be seen that the connotation construction of new engineering is closely related to the development of local social and economic industries. Therefore, it is more operable and reproducible to analyze and explore the path and method of the construction of new engineering courses in local colleges and universities from the perspective of school land integration development. 


\section{The Role Play of School and local Government in the Construction of NeW ENGINEERING}

\subsection{Role Play of Local Universities}

As of the beginning of 2018, there are 2631 colleges and universities in China, and 2512 local universities (including higher vocational colleges), accounting for $95 \%$. In the process of promoting the construction of new engineering, local colleges and universities are worthy of being an important main force. The basic orientation of the construction of new engineering courses in local colleges and universities is mainly reflected in the aspects of locality, application and industry. First, services are local. Van Hayes, former president of the University of Wisconsin in the United States, put forward such theories as "the boundary of the school is the boundary of the state" and "service should be the only ideal of the University", which well explains the orientation of service orientation of local colleges and universities. Therefore, the social function of local colleges and universities is mainly to serve the regional economic and social development, and "locality" is its most important attribute. Secondly, the cultivation of engineering technology application-oriented talents. The educational circles have basically recognized that the classification of talents can be divided into two types: research-oriented and application-oriented. Among them, applied talents are subdivided into engineering type, technical type and skill type. Under the background of great changes in China's technical structure and industrial structure, enterprises urgently need high-level engineering technology applied talents. Therefore, it is of great practical significance for local universities to combine regional advantages and their own characteristics to cultivate engineering technology application-oriented talents. Finally, technology R \& D is oriented to industrial development. The vast majority of local colleges and universities in scientific research and technological innovation compared with the advantages of engineering universities, there is no competitive advantage in the national major scientific and technological research and development, it is necessary to dislocation development. Therefore, the scientific and technological research and development of local colleges and universities should be oriented to the practical technology development, technological innovation and service required by the regional industrial structure adjustment or enterprise technological progress.

\subsection{Role Play of Regional Government Industry}

The construction of new engineering requires the strong support of regional government and the wide participation of industry and enterprises, and the integration of production and education is an important form of cooperation. At the end of 2017, the general office of the State Council issued several opinions on deepening the integration of industry and education, which strengthened the toplevel design and systematically planned the "four in one" development mode of industry education integration of government, enterprises, schools and social organizations. Therefore, in deepening the integration of industry and education, and promoting the construction of new engineering, the government mainly participates in policy supply, project approval, taxation and commendation, and becomes the service provider and coordinator of all partners. The logical starting point of regional industry, industry, enterprises and universities to build new engineering courses is resource sharing and win-win cooperation, and its role positioning is mainly reflected in two aspects. First, we should provide our own needs for joint construction. The construction of new engineering courses by school local integration should be the endogenous demand formed by regional industries, industries and enterprises in their own development.

The construction demand of local colleges and universities is determined by the attribute of Higher Education Serving Regional Economic and social development. According to the idea of "industries echo disciplines and disciplines support industries", relevant industrial enterprises in the region have established long-term and stable ties with local colleges and universities, and have taken the initiative to connect their own needs with school teaching resources and scientific and technological research and development, so as to solve the problems of lack of technology and talents encountered in economic society and enterprise development, so as to enhance the market competitiveness and development potential of enterprises At the same time, it provides convenient conditions for the development of the school. Second, give full play to the advantages of industry feedback teaching. Industry and enterprises jointly shoulder the mission of developing regional higher education by building curriculum system with local colleges and universities, building practice and training bases, and building a platform for "double qualified and double qualified" teachers ${ }^{[1]}$. 


\section{Constraints in the Construction of New Engineering Courses by School Land INTEGRATION}

How to realize the social significance of new engineering construction mainly depends on the interaction and cooperation between the school and the local government. In the practical exploration of promoting the construction of new engineering, education and industry systems have made a lot of attempts with application as the goal, forming more and more collaborative education projects. However, in reality, the two systems are still relatively independent, the degree of integration is not high, and the implementation method of new engineering construction is not systematic and complete, so it is difficult to be popularized and applied in various colleges and universities.

\subsection{The Orientation of School Running is Not Clear, Which Weakens the Overall Promotion of New Engineering}

The construction of new engineering is not the competition of scientific research achievements or hardware equipment in a single discipline, but the demonstration of the comprehensive strength of the school. Discipline integration, cross-border training, concept innovation, school governance, campus culture and other aspects will play an important role, which needs to be clarified and guaranteed from the perspective of school running orientation. But at present, the orientation and tradition of many local colleges and universities are still out of touch with the needs of local economic and social development and technological innovation requirements of first-line enterprises, which greatly weakens the overall promotion of new engineering. First, ideas are bound. The construction of new engineering courses proposed at the national level is of great guiding significance to all colleges and universities, but it is not compulsory for all colleges and universities to participate, but "conscious action" and "independent behavior" of colleges and universities. However, under the background of long-term development of science and technology, the construction of local engineering education should be directly influenced by the construction of science and technology, or by the long-term development of local engineering education And promotion path. Second, the logic of dependent development is solidified. In China's current higher education system, comprehensive researchoriented colleges and higher vocational colleges have relatively clear school running orientation, but most of the local colleges and universities with no obvious advantages lack "identity" and are in a dilemma, and they are used to following the traditional mode of running research universities upward $^{[2]}$.

\subsection{The Professional Setting Lacks Foresight and Can Not Deeply Connect with Regional Industrial Development}

The World Competitiveness Yearbook, a research achievement released by the international management and Development Institute in Lausanne, Switzerland, points out that the qualification level of Chinese engineers is at the terminal level in more than 60 countries and regions surveyed in the world. The main reason is that China's engineering education has been developing within the scope of relatively rigid professional catalog, students' knowledge is narrow, and the construction of specialty group has not fully realized the seamless connection with the development of regional industrial clusters. For a long time, the development of Engineering Specialty in local colleges and universities is limited by the inertia thinking of domestic engineering education, and generally lacks its own advantageous disciplines and specialties. The pertinence of talent training is not strong, and the competitive advantage is not obvious. Most local colleges and universities are not sensitive enough to the needs of local industry development, and can not identify the new characteristics and trends of regional industrial development in time, adjust the training objectives, optimize the professional setting, improve the training system, and realize the strategic docking of talent training and industrial development. Therefore, at present, the intellectual output of talent training in local colleges and universities is difficult to support the transformation and upgrading of local industries. In particular, there are obvious shortcomings in the cultivation of engineering and technological talents in basic, emerging and high-end fields, and there is a lack of top-notch talents who can adapt to and lead innovation and entrepreneurship, while the traditional engineering talents are relatively surplus, resulting in the structural surplus and short supply of engineering graduates Lack of contradictions. 


\subsection{The Construction of Teachers is Lagging Behind, which is Difficult to Support the Cultivation of Practical Ability of New Engineering Talents}

The strength of the teaching staff determines the quality level of talent training. The teaching staff of local colleges and universities is composed of a large number of young teachers, mainly from university graduates who are the main participants and executors of new engineering construction. However, due to the fact that young teachers' learning track is from university to university, they generally lack the experience of working in the front line of industry and enterprises and teaching practice experience. Knowledge updating stays at the theoretical stage, lagging behind the practical development of industrial technology, and there is a big gap from the requirements of new engineering construction. At the same time, the construction of new engineering courses focuses on the reform and innovation of teaching strategies and teaching methods. However, the current evaluation system of local colleges and universities tends to focus on academic achievements, focusing on academic papers and scientific research projects, and neglecting the quality of teaching, resulting in the lack of motivation for young teachers to innovate in teaching methods. However, there is no corresponding incentive mechanism for the new industries with high threshold, large investment in the early stage and small return in the late stage, which leads to the low willingness of young teachers to participate, so it is difficult to put forward significant teaching strategy reform. In addition, due to the restriction of personnel system, it is difficult for senior engineers and other professionals with rich experience to work in Colleges and universities. In the long run, the irrationality of the construction of new engineering teaching staff has been further enlarged, which ultimately affects the quality of Engineering application-oriented personnel training ${ }^{[3]}$.

\subsection{The Gap Between School and Enterprise Hinders the Matching of Engineering Talent Market}

The cultivation of engineering technology ability of new engineering talents is cross-border, which needs the cooperation of schools, local governments and industry enterprises. However, in the actual personnel training, the cooperation between the multi-agent is not smooth enough, the cooperation depth is not deep enough, and the win-win effect is not obvious ${ }^{[4]}$.

There are three reasons: first, the mechanism of school enterprise collaboration is not perfect. Although school enterprise collaboration has become an important part of the evaluation of school teaching achievements, there is still a lack of perfect system, effective cooperation mechanism and macro supporting policies; Second, the lack of independent development ability of local colleges and universities, the lack of strong sense of scientific and technological innovation, and the disconnection between supply and demand of talent training and other factors lead to the blind area of interest intersection between colleges and enterprises. In addition, the lack of cooperation platform makes it difficult to effectively achieve multi-agent collaborative education; third, the enthusiasm of enterprises to participate in collaborative training of talents is not high. Enterprises are the main body of market economy with profit as the goal. Although they also have the demand of talent planning and construction under the background of the new era, the initiative of enterprises is quite different from that of colleges and universities on the whole. In addition, most enterprises think that collaborative education increases the difficulty of enterprise management, and can not bring obvious profits, so the enthusiasm in playing the main role of collaborative education is not high.

\section{Exploration and Practice of NeW Engineering CONSTRuction From the PERSPECTIVE OF SCHOOL LOCAL INTEGRATION}

Under the background of new engineering construction, Xinglin College of Nantong University has always been based on the local conditions, and has taken the lead in putting forward the goal of "fully promoting the rise of Huai'an and building a high-level application-oriented university in an all-round way", and is committed to cultivating talents urgently needed in regional new economy and new industry.

\subsection{Strengthen the New Engineering Ethics Education Around the Basic Requirements of Moral Education and Cultivation of People}

The construction of new engineering must be deeply grasped by Xi Jinping's characteristic socialism thought in the new era and firmly establish the sense of mission and responsibility of higher education. 
We should adhere to correct guidance, strengthen ideological guidance, promote the organic integration of science education, humanities education and engineering education, and pay attention to the cultivation of students' engineering ethics consciousness. The connotation of engineering ethics is rich, among which the most basic contents are family feelings, moral quality, legal consciousness and ecological consciousness. Xinglin College of Nantong University, centering on the fundamental requirements of moral education and cultivating people, puts ideological and political work through the whole process of education and teaching, and constructs a new pattern of "all staff education, allround education and whole process education". In the exploration and transformation from "Ideological and Political Curriculum" to "curriculum ideological and political education", the school guides all disciplines and majors to revise the talent training plan, optimize the curriculum, improve the talent training and evaluation standards, and strive to cultivate a high level with strong engineering quality, high ideological and political quality, and Chinese spiritual cultivation and Chinese national temperament Applied talents.

\subsection{Building New Engineering Specialty Group Based on Industrial Demand}

With the breakthrough development of new generation information technology such as big data, cloud computing, virtual reality, mobile Internet and artificial intelligence, the global manufacturing industry has ushered in a new scientific and technological revolution and industrial revolution. As one of the Pilot Universities of national "excellent engineer" and "excellent agriculture and forestry" double plan, Xinglin College of Nantong University takes the opportunity of new engineering construction to re-examine the professional boundary, vigorously optimize the structure of disciplines and specialties, create advantageous disciplines and specialties, promote the fundamental, overall and strategic problem-solving of the whole school's engineering education reform, and realize the knowledge structure and market demand Efficiency matching. According to the actual needs and future development trend of regional new economy, the University breaks the inertia thinking and path dependence of traditional discipline construction, adheres to the industrial chain technology chain of discipline group and specialty group, closely responds to the development demand of regional industry, and creates discipline specialty cluster. At present, the University focuses on the development of disciplines closely related to intelligent manufacturing, green manufacturing and new materials. Among them, "data science and big data technology" and "robot" have been approved by the Ministry of education in 2018. We will continue to improve the discipline and specialty ecology with school characteristics, and create professional clusters such as electronic information specialty group, advanced manufacturing specialty group, agricultural food biology specialty group and chemical environment specialty group.

\subsection{Based on the Connotation of New Engineering Construction, build a New System of "Double Teachers and Double Abilities" Teaching Staff}

As the saying goes: "the train runs fast, all depends on the locomotive.". The teaching staff is like the "locomotive", which is the engine of talent training quality. Whether it is the traditional engineering construction or the new engineering construction, the teaching staff is always the premise and guarantee for carrying out the academic research in the discipline field and cultivating the discipline professionals. Xinglin College of Nantong University has always attached great importance to the construction of teachers, focusing on the cultivation of "double qualified and double competent" teachers. The school studies and promulgates a series of policies to guide the transformation and development of teachers. The "double qualified and double competent" teachers are included in the special plan for the construction of teaching staff. Every year, more than 100 teachers are sent to enterprises, scientific research institutes, government departments and other temporary positions for training, so as to improve the application ability of teachers in solving practical problems of enterprises. Young teachers are required to incorporate the "double quality improvement plan" into their personal career development plans, encourage teachers with strong application ability to obtain corresponding engineer qualification certificates, actively connect with enterprises, combine theory with practice, and constantly exercise the engineering practice application level of teachers in the school. We should strengthen the assessment management and professional title evaluation of "double qualified and double capable" teachers, and set up special funds for the construction of "double qualified and double capable" teachers. Teachers who meet the requirements are encouraged to apply for the "doctor of entrepreneurship and innovation" program in Jiangsu Province. We should expand the introduction channels of "double qualified and double capable" teachers, introduce professional 
and technical personnel with solid professional foundation, rich practical experience and basic conditions of teachers from enterprises and institutions to enrich the teaching team; we should employ qualified enterprises, artists and senior technicians from industries and enterprises to undertake relevant teaching tasks and carry out corresponding case teaching.

\subsection{Deepen School Local Integration and Build Collaborative Education Platform}

It is an important and effective way to promote the coordinated and orderly development of education, society and market, and steadily improve the quality of new engineering education by building a community of destiny among local colleges and universities, the government and industrial enterprises, and taking joint action to unify purpose rationality and value rationality

- Xinglin College of Nantong University adheres to the principle of opening school and opening up multiple paths. Focusing on improving students' ability to adapt to change and engineering innovation, Xinglin College of Nantong University has constantly strengthened the cooperation among different stakeholders such as the government, universities, enterprises and students. Through the establishment of physical colleges, virtual colleges, industry colleges, regional colleges, cross-border colleges, and innovation platforms, it has built a comprehensive system of integration A collaborative education platform covering the whole process of all disciplines and talents training. The university has improved the collaborative education mode of combination of science and education, integration of production and learning, and school enterprise cooperation, actively promote the cooperation and co construction of local universities, regional governments and industrial enterprises, and enhance the depth and breadth of cooperation. At present, the laboratory jointly built by the school, local government and industrial enterprises has achieved the full coverage of "4+2" industry in the whole city. In addition, Xinglin College of Nantong University focuses on optimizing the collaborative education platform.

\section{CONCLuSion}

It is not an overnight task to promote school local integration and promote the construction of new engineering courses. It requires both the school and the local government to comprehensively deepen the reform, keep pace with the pace of economic and social development in the new era, and walk out of a distinctive path in personnel training, so as to fully show the characteristics of the new era of the great development of school local integration with new weather and new achievements.

FUNDING SOURCE: Research on talent training mode of "new engineering" in local undergraduate colleges and universities (project code: 2019SJA2197)

\section{REFERENCES}

[1] Wang Juhong, Liu Tingting, Ma Dongyuan, Zhang long. Building a new ecology of engineering education with the integration of government, industry, University and research under the new economy [J]. Research on higher engineering education, 2017 (4): 20-26.

[2] Lu Guodong, Li tuoyu. Thinking on the path of new engineering construction and development [J]. Research on higher engineering education, 2017 (6): 20-26.

[3] Chen Tao, Shao Yunfei. Washington Agreement: Connotation interpretation and China's practice -- Also on the substantial equivalence with "new engineering" construction [J]. Chongqing higher education research, 2018, 6 (1): 56-64.

[4] Xu Xiaofei, Ding Xiaohua. Exploration on the reform of new engineering talent training mode oriented to sustainable competitiveness [J]. China University teaching, 2017 (6): 6-10.

Citation: Sun Hongxia., "Exploration and Practice of New Engineering Courses in Local Universities" International Journal of Humanities Social Sciences and Education (IJHSSE), vol 8, no. 3, 2021, pp. 103-108. doi: https://doi.org/10.20431/2349-0381.0803010

Copyright: ( ) 2021 Authors. This is an open-access article distributed under the terms of the Creative Commons Attribution License, which permits unrestricted use, distribution, and reproduction in any medium, provided the original author and source are credited. 